\title{
Nanocrystalline Mixed Oxides for the Selective Oxidation of Propane
}

\author{
Yu Zhenxing, Zheng Wei, Fu Hongying, Wu Hong, Fan Xuelei \\ Da qing Nanyuan Group Co., Ltd., \\ Da Qing, China \\ e-mail: zheng_8_wei@163.com
}

\begin{abstract}
The effects of chemical composition and preparation conditions, especially water content, calcination atmosphere and oxygen content on the catalytic performances of MoVTeNbO mixed oxide catalyst system for the selective oxidation of propane to acrylic acid have been investigated and discussed. Among the catalysts studied, the Mo1.0V0.3Te0.23Nb0.120x catalyst calcined in inert atmosphere under a temperature of $600^{\circ} \mathrm{C}$ showed the best performance in terms of propane conversion and selectivity to acrylic acid. The results revealed that proper chemical composition, calcination atmosphere, water content and oxygen content affected greatly the catalysts in many ways including structure, chemical composition, which are related to their catalytic performances, the $\mathbf{7 8 . 1 \%}$ propane conversion and $61.0 \%$ one-pass yield to acrylic acid can be achieved at the same time.
\end{abstract}

Keywords-propane; acrylic acid; selective oxidation

\section{INTRODUCTION}

Selective oxidation of propane is highly attractive because it would bypass the energy intensive endothermic steam cracking or dehydrogenation reactions currently employed to manufacture olefin intermediates from natural gas and petroleum feedstocks for subsequent oxidation. Catalytic selective oxidation of propane is motivated by both the potential economic and environmental advantages. It has recently attracted great attention in both academia and industry. The most effective catalyst system for this reaction is the MoVNbTe mixed oxide catalyst, as first patented by Mitsubishi Chemicals [1,2].

In this paper, we explored the potential of the nanoscale templating method to control the structure and surface areas of mixed MoVTeNbO system. This method relies on filling the interstitial space of the periodic arrays of colloidal latex polystyrene spheres(PSS) with a fluid containing the Mo, V, Te and $\mathrm{Nb}$ oxides sources that is subsequently converted into solid skeleton [3-11]. In the final step, the spheres are removed creating interconnected voids where the spheres were originally located and the solid skeleton in the location of the original interstitial spaces. Latex polystyrene spheres of uniform size $\left(100 \mathrm{~nm}-5 \mu_{\mathrm{m}}\right.$ in diameter) were synthesized by emulsion polymerization method [12-14]. Colloidal crystallization processes leading to various ordered closepacked structures have been extensively studied [15].The average size was controlled by the nature and concentration of the monomer, and initiator species, temperature and stirring rate [16].

This paper focused on the design of ordered arrays model MoVTeNbO catalysts with controlled structures and compositions and their application in selective oxidation of propane into avrylic acid. Systematic studies were performed by varying different synthesis parameters in order to establish the function of each component in these mixed metal oxide catalysts.

\section{EXPERIMENTAL}

Two synthesis routes were followed in the preparation of mixed MoVTeNbO catalysts. The first synthesis route used metal precursors of ammonium paramolybdate $\left(\mathrm{Mo}^{+6}\right)$, ammonium metavanadate $\left(\mathrm{V}^{+5}\right)$, telluric acid $\left(\mathrm{Te}^{+6}\right)$ and niobium oxalate $\left(\mathrm{Nb}^{5+}\right)$ corresponding to a compositional ratio of $\mathrm{Mo}_{1.0} \mathrm{~V}_{0.3} \mathrm{Te}_{0.23} \mathrm{Nb}_{0.12} \mathrm{O}_{\mathrm{n}}$. Dissolving the desired amounts of ammonium metavanadate, ammonium heptamolybdate, and telluric acid in deionized water and stirred at $80^{\circ} \mathrm{C}$ for $1.0 \mathrm{~h}$ in a flask resulted in a uniform aqueous solution. Cooling the solution to $40^{\circ} \mathrm{C}$, and then an aqueous solution of niobium oxalate having the desired niobium concentration was mixed to result in a slurry. This step was followed by the addition of $400 \mathrm{~nm}$ PSS solution [13] at the precursor/PSS ratio of 2. The mixture was mixed for 60-100 minutes before being centrifuged at 1000 rpm.The resulting solids were filtered, dried then Soxhlet extracted for $100 \mathrm{hrs}$ using acetone/THF. The extracted solids were calcined in $\mathrm{Ar}$ at $600^{\circ} \mathrm{C}$ for $6 \mathrm{hrs}$. This sample was labeled nanocrystalline mixed catalyst(NMC). Dissolving the desired amounts of ammonium metavanadate, ammonium heptamolybdate, and telluric acid in deionized water and stirred at $80^{\circ} \mathrm{C}$ for $1.0 \mathrm{~h}$ in a flask resulted in a uniform aqueous solution. Cooling the solution to $40^{\circ} \mathrm{C}$, and then an aqueous solution of niobium oxalate having the desired niobium concentration was mixed to result in a slurry. The resulting solution was evaporated to dryness and calcined in $\mathrm{Ar}$ at $600^{\circ} \mathrm{C}$ for $6 \mathrm{hrs}$. This sample was labeled conventional mixed catalyst (CMC).

Surface areas of the catalyst $\mathrm{A}$ and $\mathrm{B}$ were measured from the adsorption isotherms of $\mathrm{N}_{2}$ at $77 \mathrm{~K}$ using the BET method using a Micromeritics TriStar 3000 porosimeter. The model catalyst A and B were characterized by powder X-ray diffraction employing Siemens D500 diffractometer with $\mathrm{Cu}$ $\mathrm{Ka}$ radiation and its chemical composition determined by ICP. The SEM images were collected using Hitachi S-900 scanning electron microscope. 


\section{Results AND Discussion}

The pore size distribution of NMC catalyst is shown in Figure 1. The NMC catalyst exhibits a broad pore size distribution range of $2-100 \mathrm{~nm}$ dimensions. The NMC catalysts displayed a high surface area of $106 \mathrm{~m}^{2} / \mathrm{g}$ after Soxhlet extraction that was reduced to $90 \mathrm{~m}^{2} / \mathrm{g}$ after calcination in $\mathrm{Ar}$ at $600^{\circ} \mathrm{C}$ for $6 \mathrm{hrs}$. This surface area is 10 times higher than that of conventional mixed catalyst MoVTeNb oxides (CMC) [17]. The pore size distribution of NMC catalysts showed mesoporous structure with an average pore size around $12 \mathrm{~nm}$ in Figure 1. The pore size distribution of traditionally synthesized mixed $\mathrm{MoVTeNb}$ oxides was broader with an average pore size around $30 \mathrm{~nm}$ in Figure 1. The presence of micropores may also explain the higher BET surface area of the NMC catalyst.

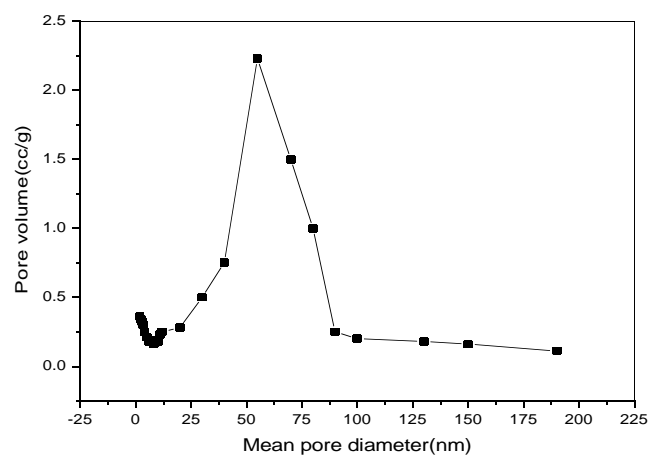

Figure 1. The pore size distribution of NMC catalyst

SEM observations were carried out to examine the morphological difference of the MSN and the traditional Scontaining (TSC) cathode without addition of MWNTs. The results are shown in Figure 2. From these test results of view, SEM confirmed these morphological features for the macroMoVTeNbO01 in Figure 2. High magnification SEM image showed the macroporous wall that is made up of nanosized crystals of $20-50 \mathrm{~nm}$ in size that created a well-defined porosity of 6-30 $\mathrm{nm}$ between these particles confirmed by the pore size distribution of macro-MoVTeNbO01 in Figure 2.

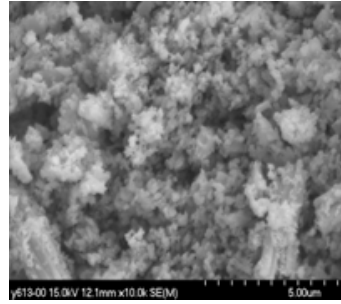

(a)

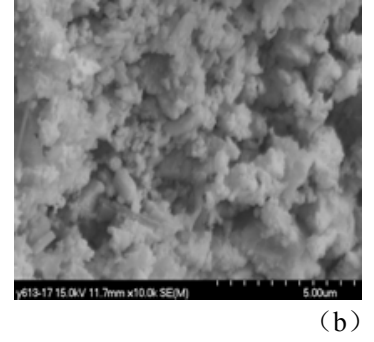

(b)
Figure 2. SEM micrographs of the surfaces of mixed catalyst with different preparation methods: (a) NMC catalyst; (b) CMC catalyst

Figure 2 shows SEM image of the tellurium sources used in the preparation of catalysts. The metallic tellurium used is composed of agglomerates with size-distribution from 5 to $20 \mathrm{~mm}$. Ball-mill grinding in the presence of hydrogen peroxide $\mathrm{H} 2 \mathrm{O} 2 / \mathrm{Te}=0.7)$ crushed the agglomerates to their primary particle size of $0.5-2.0 \mathrm{~mm}$. On the other hand, the reduction of $\mathrm{TeO}_{2}$ with hydrazine hydrate (hydrazine/Te = 2.0) revealed a fiber-like shape with a uniform section diameter of ca. $100 \mathrm{~nm}$, and lengths from 400 to $1000 \mathrm{~nm}$.

Figure 3 shows the XRD patterns of the as-dried samples corresponding to Figure 1. All the samples showed a set of diffraction lines with $2 \mathrm{u}$ at 23.08, 27.68, 38.38, 40.48, 43.38, $45.98,49.68$ which are consistent with hexagonal tellurium Figure 3 shows the XRD patterns of the as-calcined catalysts. All the catalysts showed major diffraction lines with $2 u$ at $22.18,26.18,26.68,28.28$ assigned to a hexagonal phase $\mathrm{M} 2$, and $2 \mathrm{u}$ at $6.68,7.88,22.28,27.28$ assigned to an orthorhombic phase M1 [2,17]. The ratios of phase M1 to phase M2 as expressed by the ratio of intensity of line with $2 \mathrm{u}$ at 27.28 to that at 288 varied depending on the tellurium source.

The XRD data for the presence of the $\mathrm{MoO}_{3}$ phase when using CMC catalyst supported the above assumption. By comparing the XRD pattern and performance of these catalysts, the performance of the catalyst can be seen to be closely connected with the ratio of M1 to M2; suggesting that the synthesis approaches improves catalytic performance by enhancing the formation of phase M1.

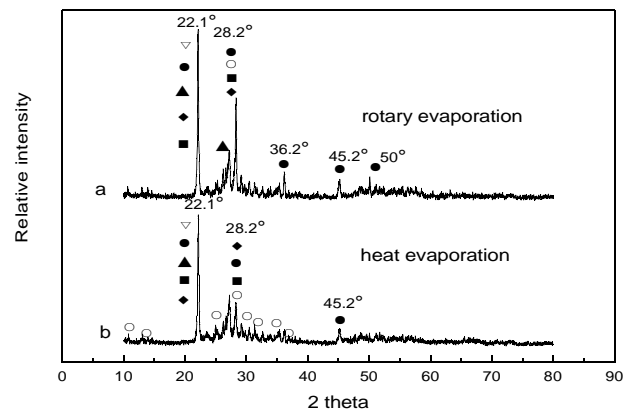

Figure 3. XRD patterns of mixed catalysts from precursors obtained via different drying methods: (a) heat evaporation; (b) rotary evaporation. (घ) $\left(\mathrm{V}_{0.07} \mathrm{Mo}_{0.93}\right)_{5} \mathrm{O}_{14},(\nabla)\left(\mathrm{Nb}_{0.09} \mathrm{Mo}_{0.91}\right) \mathrm{O}_{2.8},(\mathrm{O}) \mathrm{MoO}_{3},(\boldsymbol{\Delta}) \mathrm{Mo}_{5} \mathrm{TeO}_{16}$ and/or $\mathrm{TeMo}_{4} \mathrm{O}_{13},(\bullet) \mathrm{Te}_{4} \mathrm{Nb}_{2} \mathrm{O}_{13}(\bullet)$ TeMO (TeVMoO and/or TeVNbMoO)

\section{Conclusions}

The results of this study reveal that NMC catalyst containing nanocrystalline mixed oxides were successfully synthesized with surface areas in the range of $80-110 \mathrm{~m}^{2} / \mathrm{g}$. The macro templated synthesis approach resulted in improved control over morphology, composition and structure of the bulk mixed MoVTeNbO catalysts. Mixed metal oxide nano structures in the range of 20-50 nm were obtained with pores in the 6-20 nm range promising for selective oxidation of propane. This study showed the great promise of these novel mixed MoVTeNbO catalysts as model catalytic systems in the selective propane oxidation to acrylic acid. 


\section{ACKNOWLEDGMENT}

This work was supported by Science and Technique Key Foundation of Hei longjiang province No GC08A403.The authors gratefully acknowledge financial and experimental support from the Da Qing Petroleum Co., Ltd. The authors would like to thank Harbin Institute of Technology for BET, SEM, XRD tests and providing scientific guidance in the material characterizations.

\section{REFERENCES}

[1] T. Ushikubo, and H. Nakamura, JP Patent 94,279351 (1994).

[2] T. Ushikubo, Y. Koyasu, and S. Wajiki, JP Patent 95, 10801 (1995).

[3] M.A. Carreon, V.V. Guliants, and Chem. Commun. (2001) 1438.K. Elissa, "Title of paper if known," unpublished.

[4] A. Stein, Microporous, Mesoporous Mater. 44-45 (2001) 227.

[5] A. Imhof, and D.J. Pine, Nature 389 (1997) 948.
[6] B.T. Holland, and C.F. Blanford, A. Stein, Science 281 (1998) 538.

[7] E.E. Wijnhoven, and W.L. Vos, Science 281 (1998) 802.

[8] O.D. Velev, T.A. Jede, R.F. Lobo, and A.M. Lenhoff, Nature 389 (1997) 447.

[9] A.A. Zakhidov, R. Baughman, Z. Igbal, C. Cui, I. Khayyullin, O. Dantas, J. Marti, and V.G. Ralchenko, Nature 282 (1997) 897.

[10] P. Yang, T. Deng, D. Zhao, P. Feng, D.J. Pine, B.F. Chmelka, G.M. Whitesides, and G.D. Stucky, Science 282 (1998) 2244.

[11] Y. Xia, B. Gates, Y. Yin and Y. Lu, Adv. Mater. 12 (2000) 693.

[12] K. Esumi, "Polymer Interface and Emulsions," Marcel Dekker, New York, 1999.

[13] R.M. Fitch, "Polymer colloids: A Comprehensive Introduction," Academic Press, New York, 1997.

[14] B.T. Holland, C.F. Blanford, T.N. Do, A. Stein, and Chem. Mater. 11 (1999) 795.

[15] R.H. Ottewill, and A.R. Rennie, "Modern Aspects of Colloidal Dispersions," Kluwer, Boston, 1998.

[16] M.A Carreon, V.V. Guliants, and Chem. Commun. (2001) 1438.

[17] T. Ushikobo, EP 5,298,539 A2 (1999). 